Article

\title{
Synthesis of Zeolite Using Aluminum Dross and Waste LCD Glass Powder: A Waste to Waste Integration Valorization Process
}

\author{
Yubin Kang ${ }^{1,+}$, Basudev Swain ${ }^{1,+}{ }^{1}$, Byoungyong Im ${ }^{1}$, Jin-Ho Yoon ${ }^{1}$, Kwang Hoon Park ${ }^{2}$, \\ Chan Gi Lee ${ }^{1}$ and Dae Guen Kim ${ }^{1, *}$ \\ 1 Materials Science and Chemical Engineering Center, Institute for Advanced Engineering (IAE), \\ Yongin-Si 17180, Korea; ybkang@iae.re.kr (Y.K.); basudevswain@yahoo.com (B.S.); imby@iae.re.kr (B.I.); \\ yjh6373@iae.re.kr (J.-H.Y.); cglee@iae.re.kr (C.G.L.) \\ 2 Program in metals and Materials Process Engineering, Inha University, Incheon 22212, \\ Korea; ez@ezcastech.com \\ * Correspondence: dgkim@iae.re.kr; Tel.: +82-31-330-7419; Fax: +82-31-330-7113 \\ + Equal contributing author.
}

Received: 24 October 2019; Accepted: 14 November 2019; Published: 20 November 2019

check for updates

\begin{abstract}
In the current investigation, we synthesize zeolite using two different waste streams, such as aluminum dross and waste glass powder, for its potential application in indium and tin recovery from the leach liquor of waste liquid crystal display (LCD) glass. The aluminum dross (Al resource) and waste glass powder (Si resource) were used as raw materials for the synthesis of zeolite. Zeolite was synthesized using different weight ratios of Al dross and waste LCD glass by hydrothermal synthesis route using $\mathrm{NaOH}$. The weight ratio variations of $\mathrm{Al}$ dross and waste LCD glass in this study are 0.3:1, 0.5:1, 1:1, 2:1, 3:1, and 4:1 using $2 \mathrm{M} \mathrm{NaOH}$ hydroxide by the hydrothermal technique. The synthesized zeolite was analyzed by X-ray diffraction spectroscopy (XRD), scanning electron microscopy (SEM), and Brunauer-Emmett-Teller (BET) followed by the possible application for recovery/extraction of indium and tin from leach liquor of waste LCD glasses. The indium extraction of average $93.66 \%$, and tin extraction of $93.10 \%$ could be achieved from mixed solution indium and tin chloride. The significant achievement of the current investigation is that it can address two environment problems simultaneously, i.e., waste LCD glass and Al dross, and can be used for value recovery from waste LCD, LCD etching waste like secondary resources.
\end{abstract}

Keywords: waste-to-waste integration; secondary raw materials; $\mathrm{Al}$ dross; zeolite; indium and tin extraction

\section{Introduction}

Zeolite is a functional ceramic material having versatile physicochemical properties and thus has attracted great interest in the environmental field as one of the most important classes of catalyst, adsorbent, and ion exchanger [1,2]. The zeolites are theoretically known to have millions of crystal structures and generally exist in the form of aluminum and silicon polymerized with hydroxyl groups. Zeolites crystal are microporous hydrated aluminosilicates of tetrahedral $\mathrm{SiO}_{4}$ and $\mathrm{AlO}_{4}{ }^{-}$where $\mathrm{O}$ atoms in the corners shared between $\mathrm{SiO}_{4}$ and $\mathrm{AlO}_{4}{ }^{-}$generate pores and channels [3]. Zeolite not only occurs naturally but is also industrially synthesized for various applications $[4,5]$. The zeolite not only attracts environmental application but has also been abundantly applied in a diverse range of applications which includes water treatment [6,7], petroleum refining [8,9], gas adsorption $[10,11]$, agriculture [12,13], and green chemistry $[14,15]$. The current market size for synthetic zeolite is 
presently estimated to be 5.2 billion dollars per annum which is expected to reach 5.9 billion dollars per annum by 2023 [16].

Synthesis of zeolite from industrial wastes has been reported in the literature, which can be a reasonably promising research area for zeolite synthesis and application [3]. Yoldi et al. have reported the synthesis of zeolites from industrial wastes rich in $\mathrm{Si}$ and/or $\mathrm{Al}$, which valorizes coal fly ash, biomass ash, aluminum dross as zeolites. Jha et al. and Bukhari et al. synthesized zeolite from industrial waste like fly ash $[17,18]$. Shigemoto et al. have reported the zeolite synthesis from coal fly ash by fusion with sodium hydroxide by hydrothermal technique [19]. Zeolite synthesis from fly ash is fairly common and has been reported by several authors. Iglesia et al. reported the synthesis of zeolite from red mud, which is an industrial waste and is a mammoth challenge that is yet to be addressed [20]. Synthesis of zeolite using waste to waste stream integration valorization process can be an innovative idea that has been hardly explored in the literature.

The current investigation involves the incorporation of two waste streams like $\mathrm{Al}$ dross and waste liquid crystal display (LCD) glass for the synthesis of zeolite. In our current investigation, the different weight ratios of two wastes were used for zeolite synthesis, followed by its application in indium and tin extraction from mixed chloride solution. Zeolite was synthesized from a mixture of different weight ratios of $\mathrm{Al}$ dross and waste LCD powder. As explained above for the synthesis of zeolite, two components i.e., $\mathrm{SiO}_{4}$ and $\mathrm{AlO}_{4}{ }^{-}$are very important. Therefore, waste resources, like $\mathrm{Al}$ dross that contains aluminum or waste LCD glass that contains silicon, are considered as raw material for the synthesis of zeolite in our current study. The synthesized zeolite was analyzed by XRD, SEM, and BET followed by its possible application for the recovery/extraction process of indium and tin from leach liquor of waste LCD glasses. Depending upon the cases, the same process can be applied for indiumand tin-bearing wastes like indium tin oxide (ITO) itching industry waste and washing liquor of metal-organic chemical vapor deposition (MOCVD) reactor solution.

\section{Materials and Methods}

\subsection{Materials}

All chemicals like were of analytical grade and were used without further purification, supplied by Daejung chemical and metal Co, Ltd. (Siheung-si, Korea). Al dross ( $\left.\mathrm{MgO}, \mathrm{MgAl}_{2} \mathrm{O}_{3}\right)$ and waste displayed glass powder which are the primary source of $\mathrm{SiO}_{2}$ was used for the synthesis of zeolite. Waste displayed glass powder was obtained through a series of processes like size reduction, crushing, grinding, and heat treatment. The process flow chart for waste displayed glass powder collection is presented in Figure 1.

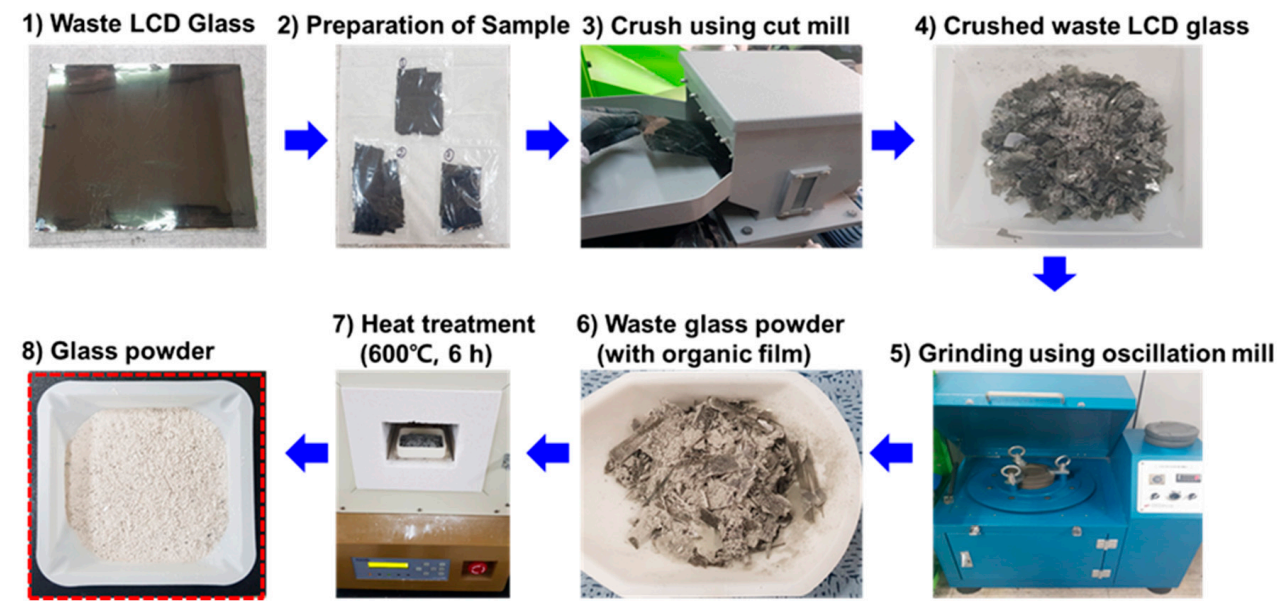

Figure 1. Process chart of waste liquid crystal display (LCD) glass powder. 


\subsection{Methods}

A complete methodology for the synthesis of zeolite from a mixture of $\mathrm{Al}$ dross $\left(\mathrm{MgO}, \mathrm{MgAl}_{2} \mathrm{O}_{3}\right)$ and waste displayed glass powder is explained in Figure 2. The particle size of both Al dross and waste displayed glass powder was analyzed by a particle size analyzer (PSA, Bluewave, Microtrac, York, PA, USA). Both the powders were mixed with different concentrations of $\mathrm{NaOH}$ by the hydrothermal process, followed by hydrothermal synthesis. The synthesized zeolite was the washed and dried. The zeolite was isolated and characterized by different techniques. The application perspective of synthesized zeolite was analyzed by using it as an adsorbent for indium and tin separation. Details of the adsorption study are explained below in the adsorption application section. Synthesized zeolite was applied for indium and tin separation with a perspective for the potential application of zeolite for the separation of indium and tin from leach liquor of waste LCD solution.

\section{Synthesis of zeolite from waste Al dross and waste glass powder}

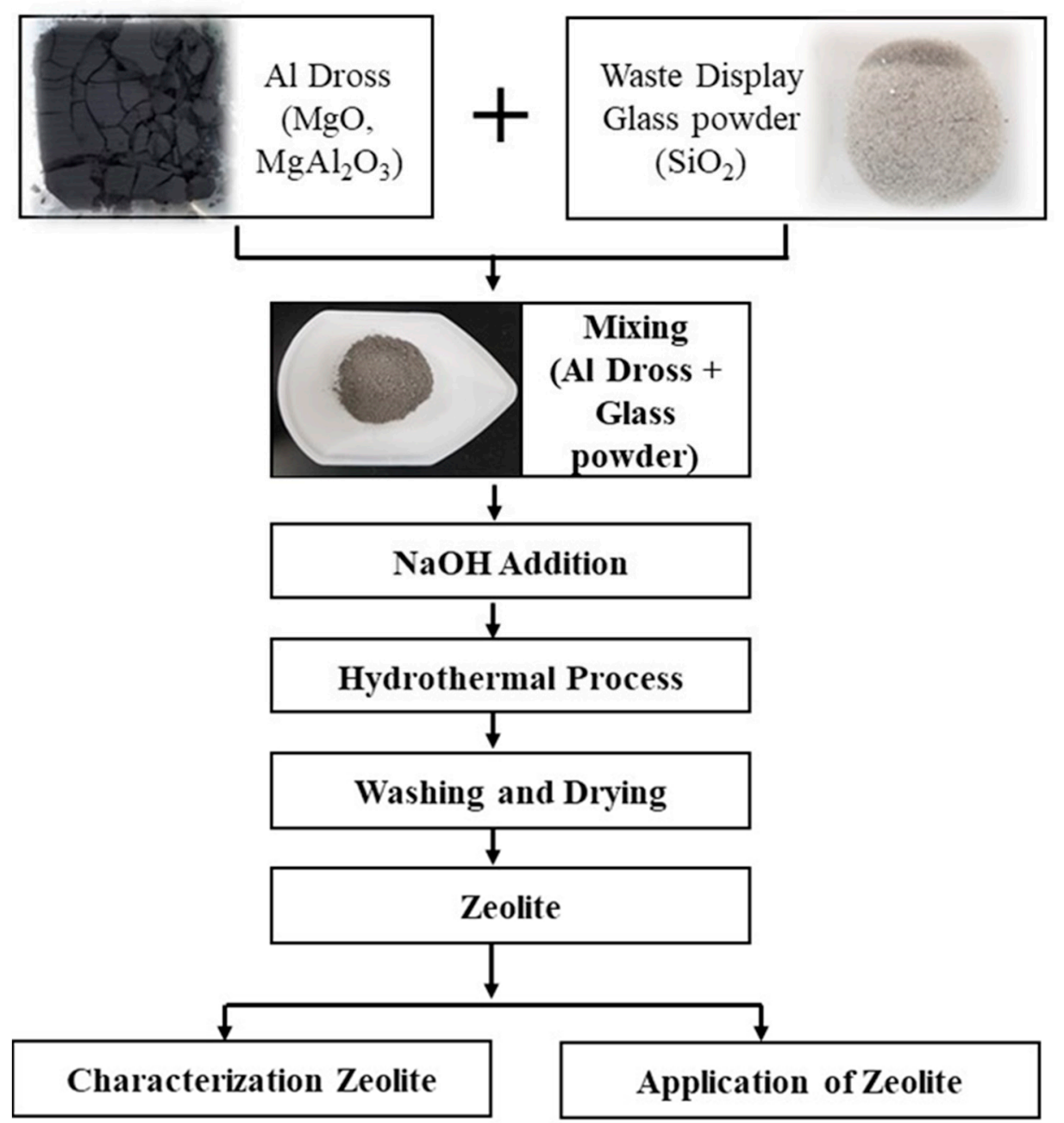

Figure 2. Experimental process followed for the synthesis of zeolite from the waste to waste stream combination.

\subsection{Characterization}

The composition of zeolite powder was analyzed by XRD (X-ray diffraction spectroscopy, XRD-6100, Shimadzu, Kyoto, Japan), XRF (X-ray fluorescence spectroscopy, ZSX Primus II, Rigaku, Tokyo, 
Japan), and MP-AES (Microwave Plasma-Atomic Emission Spectroscopy 4200, Agilent, Santa Clara, CA, USA). Nitrogen adsorption-desorption isotherm measurement was carried out for the calculation of Brunauer-Emmett-Teller (BET, TriStar II 3020, Micromeritics, Norcross, GA, USA).

\subsection{Adsorption Application}

Zeolite synthesized by the above method was used for adsorption studies. For each study, $1 \mathrm{~g}$ of zeolite was used as an adsorbent for the extraction of indium and tin mixed solution. Indium and tin mixed with chloride solution of $44 \mathrm{ppm}$ and $84 \mathrm{ppm}$, respectively was used for the investigation. The motivation for selecting indium- and tin-mixed chloride solution for the adsorption studies was for the recovery of indium from the ITO-bearing waste like LCD. Though indium concentration in ITO is major and tin concentration is minor, in our study higher concentration of tin was considered for prospective versatile application, like different indium bearing waste. The $200 \mathrm{~mL}$ of $1 \mathrm{~g}$ of zeolite was added and kept for $24 \mathrm{~h}$ under constant stirring at 200 RPM in all experimental conditions. After $24 \mathrm{~h}$ the indium and tin concentration was analyzed using MP-AES (MP-AES (Microwave Plasma-Atomic Emission Spectroscopy 4200, Agilent, Santa Clara, CA, USA).

\section{Results and Discussion}

Zeolite was synthesized using different weight ratios of Al dross and waste LCD glass by hydrothermal synthesis route using $\mathrm{NaOH}$. The particle size of both $\mathrm{Al}$ dross and waste displayed glass powder were analyzed, the average particle size was 13.41 and $5.68 \mu \mathrm{m}$, respectively. The weight ratio variations for Al dross and waste LCD glass in this study were $0.3: 1,0.5: 1,1: 1,2: 1,3: 1$, and 4:1 using $2 \mathrm{M}$ $\mathrm{NaOH}$ hydroxide. The experimental parameter used for studies is presented in Table 1 . The requisite weight ratio of $\mathrm{Al}$ dross and waste LCD glass powered were mixed thoroughly. The powder mixture of $\mathrm{Al}$ dross and waste $\mathrm{LCD}$ glass was added to $2 \mathrm{M}$ of $\mathrm{NaOH}$ at $100 \mathrm{~g} / \mathrm{L}$ into the hydrothermal reactor. The reaction was carried out at $90^{\circ} \mathrm{C}$ and $24 \mathrm{~h}$ under constant stirring of $200 \mathrm{rpm}$. After cooling, the separated zeolite was characterized by XRD and SEM. Figure 3a represents the XRD pattern for synthesized zeolite, which has been synthesized at different composition ratios. XRD in Figure 3a indicates that at lower $\mathrm{Al}$ dross composition clear and sharp XRD peaks were observed in contrary to higher $\mathrm{Al}$ dross composition where broad and comparatively less sharp XRD peaks were observed. Figure $3 \mathrm{~b}$ compares the intensity of the primary peak of synthesized zeolite which has been extracted from Figure 3a. Figure $3 \mathrm{~b}$ clearly indicates that intensity of primary peak in XRD follows the order as 0.3:1 $>0.5: 1>1: 1>2: 1>3: 1>4: 1$ for Al dross and waste LCD glass in the weight ratio variation study. Figure 3 clearly indicates that for $\mathrm{Al}$ dross lower composition ratio shows better crystallization of the zeolite.

Table 1. Experimental conditions employed for zeolite synthesis.

\begin{tabular}{ccccccc}
\hline Experiment & $\begin{array}{c}\text { Al Dross } \\
\text { Used, (g) }\end{array}$ & $\begin{array}{c}\text { Waste LCD } \\
\text { Glass, }(\mathbf{g})\end{array}$ & $\begin{array}{c}\text { Mixed } \\
\text { Powder, }(\mathbf{g})\end{array}$ & $\begin{array}{c}\text { NaOH 2 M } \\
\text { Solution, } \\
(\mathbf{m L})\end{array}$ & $\begin{array}{c}\text { Temperature, } \\
\left({ }^{\circ} \mathbf{C}\right)\end{array}$ & Time, (h) \\
\hline 1 & 40 & 10 & 12 & 120 & 90 & 24 \\
2 & 30 & 10 & 12 & 120 & 90 & 24 \\
3 & 20 & 10 & 12 & 120 & 90 & 24 \\
4 & 10 & 10 & 12 & 120 & 90 & 24 \\
5 & 5 & 10 & 12 & 120 & 90 & 24 \\
6 & 3 & 10 & 12 & 120 & 90 & 24 \\
\hline
\end{tabular}



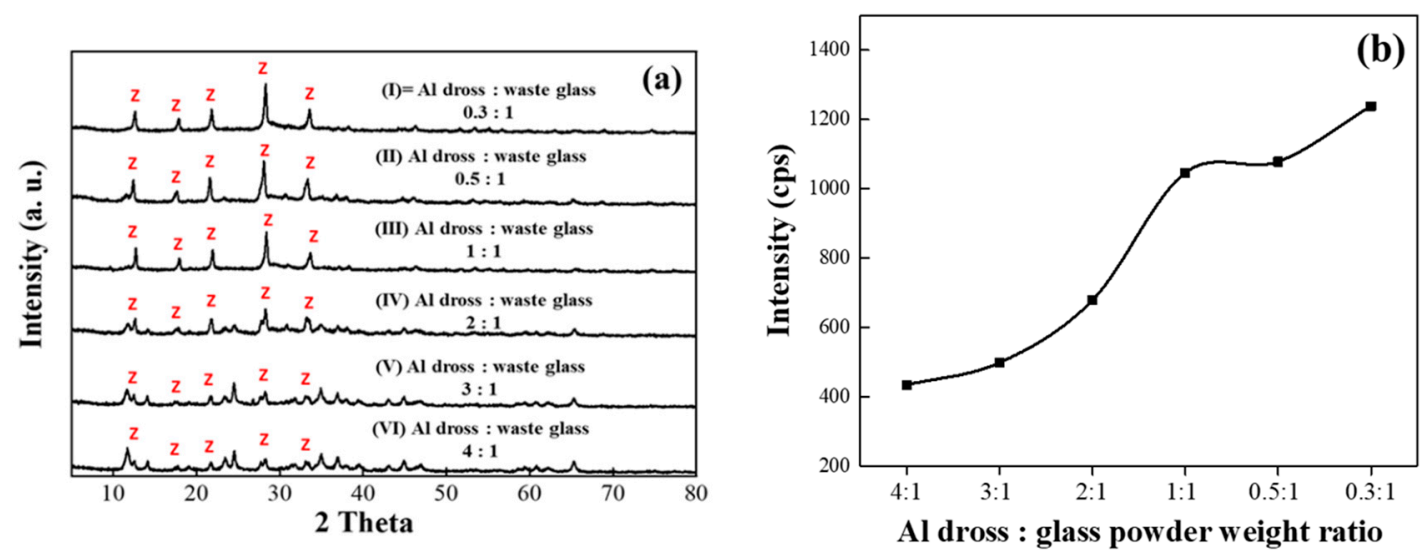

Figure 3. (a) X-ray diffraction spectroscopy (XRD) pattern of the synthesized zeolite from the waste to waste stream combination. (b) XRD intensity of the primary peak of the XRD.

Figure 4 represents the SEM images for the synthesized zeolite, which has been synthesized at different compositions, i.e., weight variation ratios for $\mathrm{Al}$ dross and waste LCD glass were 0.3:1, $0.5: 1,1: 1,2: 1,3: 1$, and 4:1. Figure 4 indicated the zeolite has various morphologies. When the weight ratio for $\mathrm{Al}$ dross and waste LCD glass was 1:1, the SEM indicated quite conglomerated. When the weight ratio of Al dross and waste LCD glass was 0.3:1, the SEM indicated that zeolite has quite an irregular shape but mostly is three-dimensional. When the weight ratio of Al dross and waste LCD glass was 2:1, the SEM indicated that zeolite has lesser conglomeration but flower-like morphology. The same figure clearly indicates that when the weight ratios of Al dross and waste LCD glass were 3:1 and 4:1, the SEM indicated that zeolite has a clear flower-like morphology.
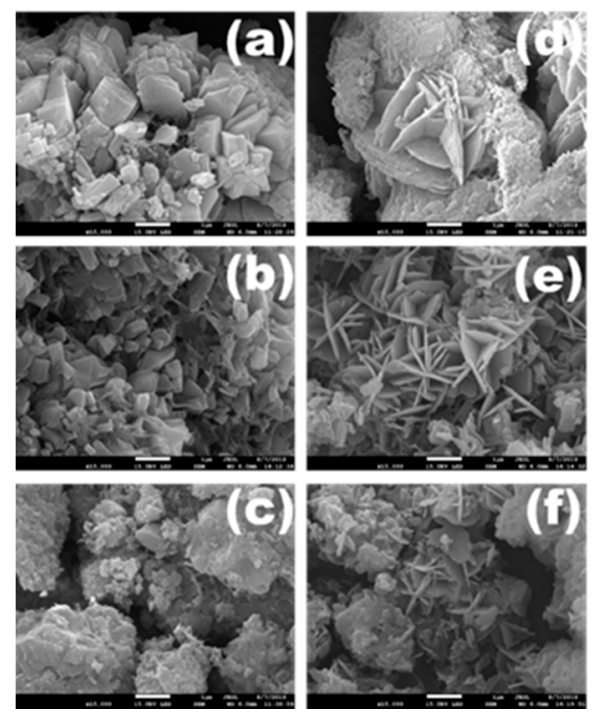

Figure 4. Scanning electron microscopy (SEM) images of the synthesized zeolite from the waste to waste stream combination, using the $\mathrm{Al}$ dross and waste LCD glass with weight ratios of (a) 0.3:1, (b) 0.5:1, (c) 1:1, (d) 2:1, (e) 3:1 and (f) 4:1 using $2 \mathrm{M} \mathrm{NaOH}$ hydroxide.

As the purpose of the zeolite synthesis was for its application in the metal separation of indium and tin by adsorption, the surface area of all synthesized zeolites was analyzed by BET. As SEM analysis of zeolite indicated the sample particles are quite heterogeneous, hence, multiple (3) BET analyses were performed for each sample and are presented in Table 2. BET analysis clearly indicated that the surface area of the zeolite synthesized had $\mathrm{Al}$ dross and waste LCD glass weight ratio variations of 
0.3:1, 0.5:1, 1:1, 2:1, 3:1, and 4:1, and using $2 \mathrm{M} \mathrm{NaOH}$ hydroxide were $23.9 \pm 2.9,26.6 \pm 4.4,27.3 \pm 1.6$, $31.6 \pm 1.9,26.4 \pm 1.8$, and $22.9 \pm 2.7 \mathrm{~m}^{2} / \mathrm{g}$, respectively.

Table 2. Brunauer-Emmett-Teller (BET) analysis for zeolite synthesized using various conditions.

\begin{tabular}{|c|c|c|c|c|c|}
\hline \multirow{2}{*}{$\begin{array}{c}\text { Al Dross: } \\
\text { Waste LCD } \\
\text { (wt/wt) }\end{array}$} & \multicolumn{5}{|c|}{ BET, $\left(\mathrm{m}^{2} / \mathrm{g}\right)$} \\
\hline & Case-I & Case-II & Case-III & Average & $\begin{array}{c}\text { BET Average, } \\
\text { Standard } \\
\text { Deviation }\end{array}$ \\
\hline $0.3: 1$ & 28.0 & 22.3 & 21.4 & 23.9 & 2.9 \\
\hline $0.5: 1$ & 32.6 & 25.0 & 22.2 & 26.6 & 4.4 \\
\hline $1: 1$ & 28.5 & 28.3 & 25.1 & 27.3 & 1.6 \\
\hline $2: 1$ & 30.2 & 34.3 & 30.5 & 31.6 & 1.9 \\
\hline $3: 1$ & 23.9 & 28.3 & 27.0 & 26.4 & 1.8 \\
\hline $4: 1$ & 26.4 & 22.5 & 19.8 & 22.9 & 2.7 \\
\hline
\end{tabular}

From the application perspective, indium and tin extrication from mixed metal solution was investigated using synthesized zeolite as an adsorbent. Each of the zeolite samples synthesized with the above process was investigated for indium and tin separation by adsorption technique. Adsorption behavior of the synthesized zeolite is depicted in Figure 5. Figure 5 indicated, after $24 \mathrm{~h}$, a significant fraction of indium and tin was adsorbed using zeolite synthesized from different weight ratios of $\mathrm{Al}$ dross and waste LCD glass. The figure indicates a fraction of metal extracted by zeolite as a function of the composition of $\mathrm{Al}$ dross and waste LCD glass weight ratio in the zeolite. The figure indicated indium extraction was independent of zeolite composition ratio whereas extraction was independent of zeolite composition. Despite Al dross composition variation in the zeolite, the indium extraction was averaged $93.66 \%$. As $\mathrm{Al}$ dross fraction decreases in the zeolite tin extraction increased, which varies from 63.50 to $93.10 \%$. Figure 5 indicates that indium and tin separation is not quite efficient, but, using synthesized zeolite both the metal can be extracted quantitatively. Figure 5 clearly opens the opportunity for prospective application of zeolite for indium and tin recovery from leach solution even at a very dilute solution.

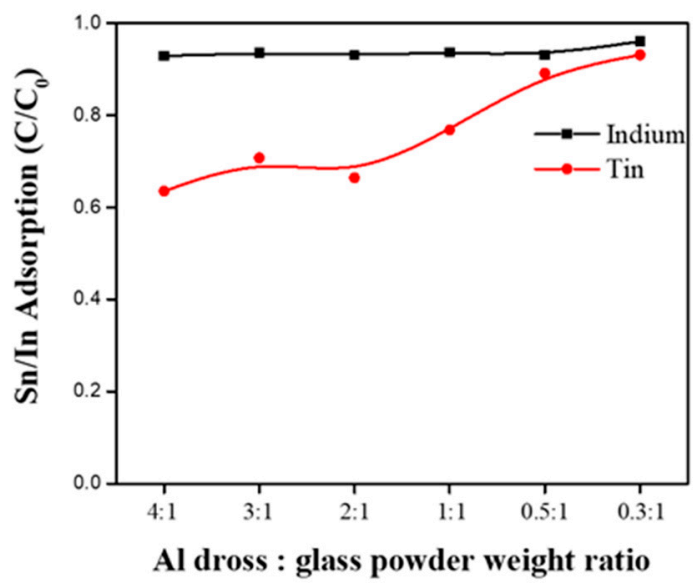

Figure 5. Adsorption of the behavior of the synthesized zeolite from the waste to waste stream combination.

Potentially, the synthesized zeolite can be applied for indium and tin concentration, extraction, and recovery. Indium and tin are the main compositions in various wastes, like LCD, LCD itching industry wastewater, and MOCVD reactor wash liquor which are challenging for indium recovery. More particularly, waste LCD glass is one of the largest volumes of e-waste generated associated with indium recovery. Indium recovery challenged from waste LCD glass is, (i) followed by single-stage 
leaching, the indium and tin concentration is very low, discourages industrial recovery [21-23]; (ii) enrichment of leach liquor is quite challenging [24,25]; (iii) from very dilute solution, indium and tin recovery can lead to disproportionate volume of wastewater generation; (iv) higher energy consumption which potentially negates the carbon footprint LCD recycling. Figure 5 indicated both indium and tin can be quantitatively extracted, which can be enriched by desorption. Followed by adsorption-desorption indium and tin enrichment, our developed process reported elsewhere can be integrated for purification of indium and recovery of tin. Figure 6 represents potential application flowsheet where indium can be recovered from leach liquor of waste LCD through leaching. Figure 6 indicated the leach liquor can be generated using the optimum condition reported in our earlier investigation elsewhere [21]. The primary challenge for indium recovery from LCD waste is associated with a low concentration of indium and tin in the leach liquor, which can be overcome through adsorption and elution using synthesized zeolite. Once, leach liquor concentrated, the indium and tin can be purified using the solvent extraction, which has been reported by Swain et al. elsewhere [25-27]. In the solvent extraction process Tin can selectively be scrubbed out using Cyanex 272 from the leach liquor leaving indium in raffinate solution. From the raffinate solution, the indium can be recovered using D2EPHA as an extractant. By the process, both the extractants, i.e., Cyanex 272 and D2EPHA can be regenerated and reused, which can close the loop and can be benefited from the cost-effective perspective.

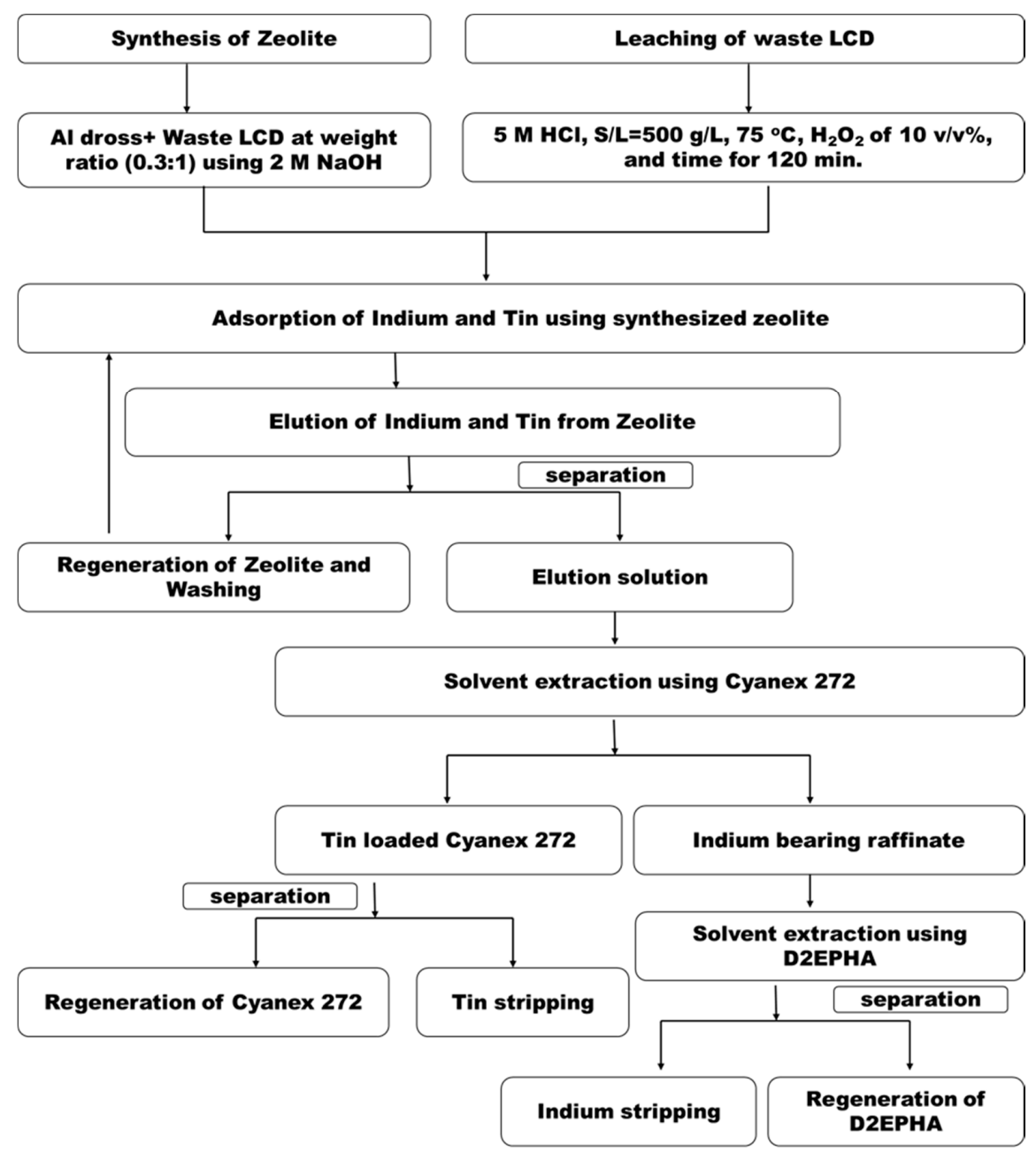

Figure 6. Potential application flowsheet where indium can be recovered from leach liquor of waste LCD through leaching using Zeolite. 


\section{Conclusions}

Zeolite was synthesized from a mixture of waste to waste stream combination like Al dross and waste LCD glass which is potentially applied for possible concentration indium and tin from leach liquor of waste LCD glass. The significant achievement of the current investigation is intended to address two environment problems simultaneously, i.e., waste LCD glass and $\mathrm{Al}$ dross, and can be used for value recovery from waste LCD, LCD etching waste like secondary resources.

Author Contributions: Formal analysis, B.S.; investigation, Y.K., B.I.; resources, D.G.K.; J.-H.Y., data curation, Y.K., B.I.; writing — original draft preparation, J.-H.Y., B.S.; writing—review and editing, B.S.; visualization, B.S., C.G.L.; supervision, B.S., D.G.K.; project administration, J.-H.Y., D.G.K.; funding acquisition, D.G.K., C.G.L., K.H.P.

Funding: This study was supported by the Energy Efficiency \& Resources of the Korea Institute of Energy Technology Evaluation and Planning (KETEP) grant funded by the Korea Government Ministry of Knowledge Economy (No. 20162020107870).

Conflicts of Interest: All the authors of the papers declare no conflict of interest.

\section{References}

1. Naushad, M.; Al-Othman, Z.A. Ion Exchange Technology II: Applications; Inamuddin, M.L., Ed.; Springer: Berlin, Germany, 2012; pp. 217-235.

2. Dąbrowski, A. Adsorption-from theory to practice. Adv. Colloid Interface Sci. 2001, 93, 135-224. [CrossRef]

3. Yoldi, M.; Fuentes-Ordoñez, E.G.; Korili, S.A.; Gil, A. Zeolite synthesis from industrial wastes. Microporous Mesoporous Mater. 2019, 287, 183-191. [CrossRef]

4. Li, Y.; Li, L.; Yu, J. Applications of zeolites in sustainable chemistry. Chem 2017, 3, 928-949. [CrossRef]

5. Jha, B.; Singh, D.N. A review on synthesis, characterization and industrial applications of fly ash zeolites. J. Mater. Educ. 2011, 33, 65.

6. Wang, S.; Peng, Y. Natural zeolites as effective adsorbents in water and wastewater treatment. Chem. Eng. J. 2010, 156, 11-24. [CrossRef]

7. Pendergast, M.M.; Hoek, E.M.V. Porous $\mathrm{LiMn}_{2} \mathrm{O}_{4}$ nanorods with durable high-rate capability for rechargeable Li-ion batteries. Energy Environ. Sci. 2011, 4, 3668-3675.

8. Degnan, T.F. Applications of zeolites in petroleum refining. Top. Catal. 2000, 13, 349-356. [CrossRef]

9. Vermeiren, W.; Gilson, J.P. Impact of zeolites on the petroleum and petrochemical industry. Top. Catal. 2009, 52, 1131-1161. [CrossRef]

10. Li, J.R.; Tao, Y.; Yu, Q.; Bu, X.H.; Sakamoto, H.; Kitagawa, S. Selective gas adsorption and unique structural topology of a highly stable guest-free zeolite-type MOF material with $\mathrm{N}$-rich chiral open channels. Chemistry 2008, 14, 2771-2776. [CrossRef]

11. Qin, J.-S.; Du, D.-Y.; Li, W.-L.; Zhang, J.-P.; Li, S.-L.; Su, Z.-M.; Wang, X.-L.; Xu, Q.; Shao, K.-Z.; Lan, Y.-Q. $\mathrm{N}$-rich zeolite-like metal-organic framework with sodalite topology: high CO 2 uptake, selective gas adsorption and efficient drug delivery. Chem. Sci. 2012, 3, 2114-2118. [CrossRef]

12. Ramesh, K.; Reddy, D.D. Advances in Agronomy; Sparks, D.L., Ed.; Elsevier: Amsterdam, The Netherlands, 2011; Volume 113, pp. 219-241.

13. Noori, M.; Zendehdel, M.; Ahmadi, A. Using natural zeolite for the improvement of soil salinity and crop yield. Toxicol. Environ. Chem. 2006, 88, 77-84. [CrossRef]

14. Clark, J.H. Solid acids for green chemistry. Acc. Chem. Res 2002, 35, 791-797. [CrossRef] [PubMed]

15. Zhan, B.Z.; White, M.A.; Sham, T.K.; Pincock, J.A.; Doucet, R.J.; Rao, K.V.; Robertson, K.N.; Cameron, T.S. Zeolite-confined nano-RuO2: A green, selective, and efficient catalyst for aerobic alcohol oxidation. J. Am. Chem. Soc. 2003, 125, 2195-2199. [CrossRef]

16. Collins, F.; Rozhkovskaya, A.; Outram, J.G.; Millar, G.J. A Critical review of waste resources, synthesis, and applications for Zeolite LTA. Microporous Mesoporous Mater. 2020, 291, 109667. [CrossRef]

17. Jha, B.; Singh, D.N. Fly ash Zeolites: Innovations, Applications, and Directions; Springer: Berlin, Germany, 2016; Volume 78.

18. Bukhari, S.S.; Behin, J.; Kazemian, H.; Rohani, S. Conversion of coal fly ash to zeolite utilizing microwave and ultrasound energies: a review. Fuel 2015, 140, 250-266. [CrossRef] 
19. Shigemoto, N.; Hayashi, H.; Miyaura, K. Selective formation of Na-X zeolite from coal fly ash by fusion with sodium hydroxide prior to hydrothermal reaction. J. Mater. Sci. 1993, 28, 4781-4786. [CrossRef]

20. La Iglesia, A.; González, M.V.; Dufour, J. Zeolite synthesis employing alkaline waste effluents from the aluminum industry. Environ. Prog. 2002, 21, 105-110. [CrossRef]

21. Swain, B.; Mishra, C.; Hong, H.S.; Cho, S.S. Beneficiation and recovery of indium from liquid-crystal-display glass by hydrometallurgy. Waste Manag. 2016, 57, 207-214. [CrossRef]

22. Swain, B.; Lee, C.; Hong, H. Value Recovery from Waste Liquid Crystal Display Glass Cullet through Leaching: Understanding the Correlation between Indium Leaching Behavior and Cullet Piece Size. Metals 2018, 8, 235. [CrossRef]

23. Yang, J.; Ekberg, C.; Retegan, T. Optimization of Indium Recovery and Separation from LCD Waste by Solvent Extraction with Bis(2-ethylhexyl) Phosphate (D2EHPA). Int. J. Chem. Eng. 2014, 2014, 1-9. [CrossRef]

24. Yang, J.; Retegan, T.; Ekberg, C. Indium recovery from discarded LCD panel glass by solvent extraction. Hydrometallurgy 2013, 137, 68-77. [CrossRef]

25. Swain, B.; Lee, C.G. Commercial indium recovery processes development from various e-(industry) waste through the insightful integration of valorization processes: A perspective. Waste Manag. 2019, 87, 597-611. [CrossRef] [PubMed]

26. Swain, B.; Mishra, C.; Hong, H.S.; Cho, S.-S. Treatment of indium-tin-oxide etching wastewater and recovery of In, Mo, Sn and $\mathrm{Cu}$ by liquid-liquid extraction and wet chemical reduction: A laboratory scale sustainable commercial green process. Green Chem. 2015, 17, 4418-4431. [CrossRef]

27. Swain, B.; Mishra, C.; Hong, H.S.; Cho, S.-S.; Lee, S.K. Commercial process for the recovery of metals from ITO etching industry wastewater by liquid-liquid extraction: simulation, analysis of mechanism, and mathematical model to predict optimum operational conditions. Green Chem. 2015, 17, 3979-3991. [CrossRef]

(C) 2019 by the authors. Licensee MDPI, Basel, Switzerland. This article is an open access article distributed under the terms and conditions of the Creative Commons Attribution (CC BY) license (http://creativecommons.org/licenses/by/4.0/). 